\title{
Research on the Renewable Energy Investment Performance and Influence Factors
}

\author{
Dong SUN ${ }^{1, a}$, Xue-Ping JIANG ${ }^{2, b,{ }^{*}}$ \\ ${ }^{1,2}$ School of Business and Administration, North China Electric Power University, Beijing, China \\ asundong@ncepu.edu.cn, bpingpinglier@163.com \\ ${ }^{*}$ Corresponding author
}

Keywords: Renewable energy, Investment performance, Influence factors, DEA.

\begin{abstract}
In this paper, Data Envelopment Analysis (DEA) will be used on the analysis of the development trend of China's renewable energy investment efficiency. We find that China's renewable energy investment efficiency overall well developed. We also find that international political and economic environment, the domestic industry development policy impact on the investment efficiency. Favorable renewable energy policies have major significance on the development of renewable energy in China, but there is a certain lag response on the effectiveness of the policy. The adverse effects of the protectionism in international trade for the development of renewable energy cannot be ignored.
\end{abstract}

\section{Introduction}

China has become the world's first country in the renewable energy sources investment in 2012[1]. However, the current development of the industry still exist some problems, such as a low level of technology, industrial development is not balanced[2], industry uncompetitive[3] and other issues. These problems may be constrained by the current imbalance in the development of domestic and international policy environment, or the failure of the investment achieves to maximize effectiveness. In view of this, based on current domestic and foreign policy of renewable energy and market environment, it is very necessary to measure the effectiveness of the current investment. We should make it clear whether the overall investment is valid and find the reasons leading to the result. So that industrial investment can be more rational and thus make the layout of the renewable energy industry, industrial structure more reasonable.

Corporate investment performance refers to the managers making a reasonable evaluation on the efficiency of investment behavior and results[4]. Its essence is the ratio of effective investment results and inputs, which is the effectiveness of corporate investment activities[5]. This article refers to renewable energy investment performance, and evaluates the overall investment efficiency, resource allocation status, technical efficiency from a macro view.

This article is divided into two parts: evaluation about renewable energy investment performance and analysis on the factors affecting the development of the renewable energy renewable. First, we will make a comparison between the United States, Europe, Brazil, India and China in renewable energy investment performance. Performance measurement is actually a measure of investment in the renewable energy industry inputs and outputs. We can draw up China's renewable energy investment efficiency in the global scope by the comparison. Secondly, we will compare the linkage between investment efficiency trends and influencing factors, in order to find the impact of a variety of external environment, and then get the influence factors of renewable energy investment, finally make recommendations accordingly.

\section{Methodology}

DEA is a method for evaluating the efficiency of non-parametric methods, which is widely used 
at home and abroad. This article will solve CRS, VRS and NIRS models by DEAP2.1 version software.

CRS model: Suppose there are N kinds of decision-making unit (DMU), each decision unit has K kinds of input and $\mathrm{M}$ kinds of output, for the $\mathrm{i}$-th DMU, xi and yi are denoted to respect. Using input-output ratio u'yi/v'xi to represent each DMU's efficiency, $u$ is the output weight vector, $v$ is the input weight vector. To avoid infinitely solutions, increasing restrictions $v$ 'xi $=1$, and translate into dual linear programming problems, the maximization of production efficiency linear expression is:

$$
\begin{aligned}
& \min \theta, \lambda \theta \\
& \text { s.t.-yi+Y } \lambda \geq 0, \theta x i-X \lambda \geq 0, \lambda \geq 0
\end{aligned}
$$

In this linear expression, yi is a scalar, represents the $\mathrm{i}$-th DMU efficiency score, its value is not more than 1 . When $\theta=1$, it indicates that the decision unit is valid, otherwise is invalid. $\lambda$ is a constant matrix of $\mathrm{N} \times 1$.

VRS model: Technical Efficiency (TE) obtained by CRS is susceptible to Scale Efficiency (SE). VRS model can separate this confusing. Its linear programming model is as follows:

$$
\begin{aligned}
& \min \theta, \lambda \theta \\
& \text { s.t.-yi+Y } \lambda \geq 0, \theta x i-X \lambda \geq 0, N 1 ` \lambda=1, \lambda \geq 0
\end{aligned}
$$

N1 represents $\mathrm{N} \times 1$ matrix. So, we can separate TE scores of CRS model into two parts, one is the scale efficiency, the other is pure technical efficiency. We calculate the same set of TE score by CRS and VRS, if they are not the same, it shows that there is a scale of DMU invalid problems.

NIRS model: In order to determine its economies of scale refers to increment or decrement, we need use NIRS method, the planning model is as follows:

$$
\begin{aligned}
& \min \theta, \lambda \theta \\
& \text { s.t.-yi+Y } \lambda \geq 0, \theta x i-X \lambda \geq 0, N 1 ` \lambda \leq 1, \lambda \geq 0
\end{aligned}
$$

If the TE score obtained by NIRS is consistent with the VRS TE score, it means the decreasing economies of scale, otherwise means the increasing economies of scale.

\section{Performance Evaluation}

In this section, we will give an evaluation on the relative effectiveness of China's renewable energy investments on a global scale, and find the gap between China and the world in renewable energy investments. According to China's economic development level, we select the USA, Europe and India, Brazil as a DMU. We take the input variables and sub-sector output variables into consideration. Because renewable energy investments and the impact on the output are both reflected in funds, we choose the total investment amount of the economies as input variables. The investment variables are total renewable energy investment in each year in China. At the same time, taking the availability of data into account, we choose the generating capacity of renewable, fuel production and consumption of renewable as the output variables of sub-sector.

\section{Data Description}

We select 2012 data for analysis, and finish the following table based on 2013 renewable energy investment trends [6]: 
Table 1 Total renewable energy investments of five economies

\begin{tabular}{|c|c|}
\hline Country & New Investment(2012)(\$bn) \\
\hline USA & 36.0 \\
\hline BRA & 5.4 \\
\hline ERU & 79.9 \\
\hline CHN & 66.6 \\
\hline IND & 6.5 \\
\hline
\end{tabular}

The renewable energy power generation (Billion Kilowatt / hours), biomass fuel production (Thousand Barrels / Day), biomass fuel consumption (Thousand Barrels / Day) of five economies are in the following table:

Table 2 Five economies`renewable energy output data[7]

\begin{tabular}{|c|c|c|c|}
\hline COUNTRY & $\begin{array}{c}\text { Renewable energy } \\
\text { power generation }\end{array}$ & $\begin{array}{c}\text { Biomass fuel } \\
\text { production }\end{array}$ & Biomass fuel consumption \\
\hline USA & 527.48973 & 971.72877 & 898.89041 \\
\hline BRA & 459.0502 & 438.05804 & 377.41906 \\
\hline ERU & 933.3455 & 250.491 & 343.843 \\
\hline CHN & 800.967 & 46.8 & 45 \\
\hline IND & 160.361 & 8 & 8 \\
\hline
\end{tabular}

\section{Result Analysis}

First, assuming the economies of scale are constant, we can obtain five economies`TE values by solving CRS model which reflects their technical efficiency (TE).

Table 3 CRS calculation results

\begin{tabular}{|c|c|}
\hline COUNTRY & TE \\
\hline USA & 0.357 \\
\hline BRA & 1.000 \\
\hline ERU & 0.137 \\
\hline CHN & 0.141 \\
\hline IND & 0.290 \\
\hline
\end{tabular}

Since TE value includes the impact of SE to each DMU efficiency value under the CRS assumption. So we should solve the model twice under the VRS assumption to separate the impact. The results are as follows:

Table 4 VRS calculation results

\begin{tabular}{|c|c|c|c|c|}
\hline DMU & CRSTE & VRSTE & SE & SCALE \\
\hline USA & 0.357 & 1.000 & 0.357 & drs \\
\hline BRA & 1.000 & 1.000 & 1.000 & - \\
\hline ERU & 0.137 & 1.000 & 0.137 & drs \\
\hline CHN & 0.141 & 0.887 & 0.159 & drs \\
\hline IND & 0.290 & 0.831 & 0.349 & irs \\
\hline
\end{tabular}

The results show that the VRSTE of the USA, Europe, China and India are different from their CRSTE, which means the presence of an invalid economy of scale in these four economies, namely they are not in an state of optimal production capacity. Pure TE in the USA, Brazil and Europe are 1, while China and India's pure TE are less than 1. It means there is a gap at the technical level with the other three countries. Our maximum capacity in getting output needs to be further improved in the case of a given input. China, the USA, Europe and India have problems of an invalid economy 
of scale, and the former three are suffering from diminishing return to scale.

\section{Influence Factors Analysis}

In this section, we will give an evaluation about the renewable energy investment efficiency in China since 2004 by DEA, and look a time-series data since 2004 as the DMU for trend analysis.

\section{Data Description}

Looking China's total amount of renewable energy investment as an input variable. Meanwhile, taking the availability of authoritative data, representativeness and non-negative of output data and other factors into consideration, we build an index system in the following table:

Table 5 Renewable energy investment performance measurement system

\begin{tabular}{|c|c|c|}
\hline Index & Definition & Calculation formula \\
\hline $\begin{array}{c}\text { The proportion of } \\
\text { renewable energy } \\
\text { power generation }\end{array}$ & $\begin{array}{c}\text { Renewable energy power } \\
\text { generation accounted for the } \\
\text { proportion of the total power } \\
\text { in our country. }\end{array}$ & $\begin{array}{c}\text { Renewable energy power } \\
\text { generation/ the proportion of } \\
\text { the total power }\end{array}$ \\
\hline $\begin{array}{c}\text { The proportion of } \\
\text { renewable energy } \\
\text { consumption }\end{array}$ & $\begin{array}{c}\text { Renewable energy } \\
\text { consumption accounted for } \\
\text { the proportion of total } \\
\text { energy consumption. }\end{array}$ & $\begin{array}{c}\text { Renewable energy } \\
\text { consumption/ total energy } \\
\text { consumption }\end{array}$ \\
\hline Energy using intensity & $\begin{array}{c}\text { The energy consumption for } \\
\text { per unit of gross domestic } \\
\text { product (GDP) required. }\end{array}$ & energy consumption/GDP \\
\hline
\end{tabular}

In order to ensure the consistency of data for each DMU, we make en efficiency evaluation for the renewable energy development during 2004 to 2011 . The data is presented in the following table:

Table 6 Renewable energy input and output data in China[8]

\begin{tabular}{|c|c|c|c|c|c|c|c|c|}
\hline & 2004 & 2005 & 2006 & 2007 & 2008 & 2009 & 2010 & 2011 \\
\hline $\begin{array}{c}\text { New investments in } \\
\text { renewable energy } \\
(\$ \text { bn })\end{array}$ & 2.6 & 5.8 & 10.2 & 15.8 & 25.0 & 37.2 & 40.0 & 54.7 \\
\hline $\begin{array}{c}\text { The proportion of } \\
\text { renewable energy } \\
\text { power generation } \\
(\%)\end{array}$ & 16.21 & 15.99 & 15.40 & 15.13 & 17.55 & 17.81 & 19.05 & 16.83 \\
\hline $\begin{array}{c}\text { The proportion of } \\
\text { renewable energy } \\
\text { consumption (\%) }\end{array}$ & 6.46 & 6.58 & 6.49 & 6.58 & 7.47 & 7.57 & 8.37 & 7.75 \\
\hline $\begin{array}{c}\text { Energy using } \\
\text { intensity }\end{array}$ & 1.34 & 1.28 & 1.20 & 1.06 & 0.93 & 0.90 & 0.81 & 0.74 \\
\hline
\end{tabular}

\section{Result Analysis}

Then we solve the CRS model to obtain TE values of five economies, which reflect their technical efficiency. 
Table 7 CRS calculation results

\begin{tabular}{|c|c|}
\hline Firm & TE \\
\hline 1 & 0.057 \\
\hline 2 & 0.084 \\
\hline 3 & 0.082 \\
\hline 4 & 0.120 \\
\hline 5 & 0.168 \\
\hline 6 & 0.256 \\
\hline 7 & 0.457 \\
\hline 8 & 1.000 \\
\hline
\end{tabular}

We should solve the model twice under the VRS assumption to separate the impact. The results are as follows:

Table 8 VRS calculation results

\begin{tabular}{|c|c|c|c|c|}
\hline Firm & CRSTE & VRSTE & Scale & Firm \\
\hline 1 & 0.057 & 0.509 & 0.112 & drs \\
\hline 2 & 0.084 & 1.000 & 0.084 & drs \\
\hline 3 & 0.082 & 0.654 & 0.125 & drs \\
\hline 4 & 0.120 & 0.895 & 0.134 & drs \\
\hline 5 & 0.168 & 0.313 & 0.535 & drs \\
\hline 6 & 0.256 & 0.312 & 0.819 & drs \\
\hline 7 & 0.457 & 0.853 & 0.535 & drs \\
\hline 8 & 1.000 & 1.000 & 1.000 & - \\
\hline
\end{tabular}

Time series data is used to analyze the trend of the development of renewable energy, the line chart is as follows:

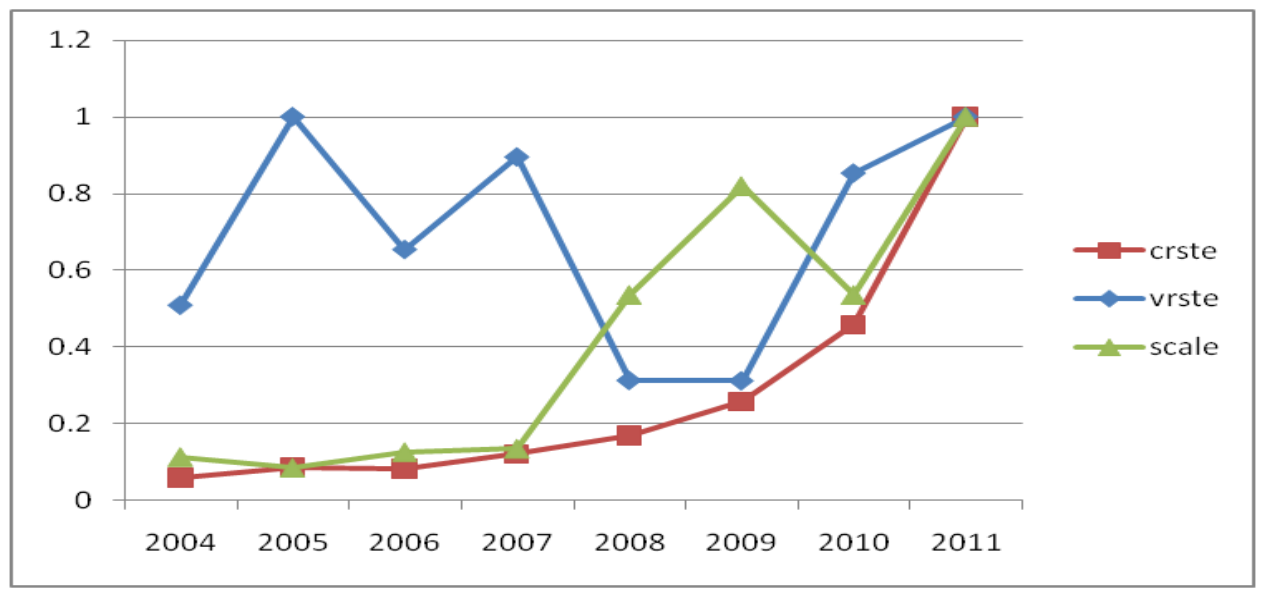

Figure 1 2004-2011 renewable energy investment efficiency trends

The figure shows that from 2004 to 2011, the overall efficiency of investment as 1 only in 2011 . It means China's renewable energy investments achieve the overall efficiency only in 2011 during 8 years, that is, the annual investment are invalid in these 8 years except 2011. However, although DMU in 2005 is overall invalid, the pure TE get 1, which means the technology is relatively effective in 2005. On the other hand, the overall efficiency of renewable energy investments is on the rise, especially in 2009, 2010 and 2011. Pure TE fluctuates greatly in 2004-2011, and not exhibits a fixed direction. In 2005 and 2011, the pure TE shows effective state. Pure TE of renewable energy gets 0.5 or more during these 8 years except 2008 and 2009. Scale efficiency fluctuate presents the overall upward trend except for a few years. 


\section{Conclusion}

China's renewable energy investments achieved technology and scale efficiency in 2011, indicating the well improves as a whole. Especially in 2008 and 2009 we achieved a breakthrough. Our analysis shows that the policy guidance has significance on the renewable energy investment efficiency, but there is a certain lag effect in current renewable energy policy. International economic environment and the negotiation results of Climate Conference have a certain influence on China's renewable energy investments. What's more, the negative impact of international trade protectionism on China's renewable energy development cannot be ignored.

China needs to improve the overall efficiency of renewable energy investment by learning technology from developed countries, and optimize the allocation of resources industry. The investment scale also need further rational planning by learning other countries. Policies are significant to development of China's renewable energy industry. On one hand, we should draw up cautious and reasonable system as the guidance. On the other hand, we also need to cultivate the relevant market. The wind power and PV have been affected sequentially by the international trade protectionism in 2010 and 2011, so China's renewable energy companies need to enhance risk awareness and preventive measures.

\section{References}

[1] Bloomberg, NEW, ENERGY, FINANCE. GLOBAL TRENDS IN RENEWABLE ENERGY INVESTMENT 2013, R. Frankfurt School: Frankfurt school UNEP collaborating centre, 2013.

[2] Li Hong, Dong Liang, Duan Hongxia. On Comprehensive Evaluation and Optimization of Renewable Energy Development in China, J. Resources Science. 3(2011) 431-440.

[3] Liu Zhiyi. The Challenge in the Development of Renewable energy in China, J. China Price. 10(2013) 79-82.

[4] He Wan, Zhong Fusen, Chang Yan. Study on Investment Performance Evaluation of Grid Enterprise ,J. Technology Economics. 1(2011) 78-84.

[5] Yang Yinsheng, Zhang Chong. An Analysis of Agricultural Listed Companies Investment Performance based on DEA-Benchmarking Model ,J. Journal of Agrotechnical. 6(2009) 91-95.

[6] Bloomberg, NEW, ENERGY, FINANCE. GLOBAL TRENDS IN RENEWABLE ENERGY INVESTMENT 2014, R. Frankfurt School: Frankfurt school UNEP collaborating centre, 2014.

[7] Information on http://www.eia.gov/

[8] Information on http://www.stats.gov.cn/ 